Bentham OPEN
CrossMark
Content list available at: www.benthamopen.com/TODENTJ/

RESEARCH ARTICLE

\title{
Tooth Size in Patients with Mild, Moderate and Severe Hypodontia and a Control Group
}

\author{
Khaled Khalaf* \\ Department of Orthodontics, King Faisal University, Al Ahsa, KSA
}

Received: December 2, 2015

Revised: June 15, 2016

Accepted: July 12, 2016

\begin{abstract}
:
Objectives:

To compare tooth size between subjects with mild, moderate and severe hypodontia and a control group.

\section{Material and Methods:}

The study comprised 120 patients with hypodontia divided into three groups of 40 mild ( $\leq 2$ teeth congenitally missing), 40 moderate (3-5 teeth congenitally missing) and 40 severe ( $\geq 6$ teeth congenitally missing) hypodontia; and 40 age and sex matched controls. Tooth size was recorded by measuring the mesiodistal and buccolingual dimensions of all fully erupted teeth on study models using digital callipers and compared between all hypodontia and control groups using Two-way ANOVA and Post Hoc Tests of subgroup comparison.
\end{abstract}

\section{Results:}

Two-way ANOVA revealed patients with hypodontia had significantly smaller mesiodistal and buccolingual tooth dimensions compared with controls $(p<0.05)$. Furthermore patients with more severe hypodontia demonstrated significantly smaller tooth dimensions than those in the mild and moderate hypodontia subgroups $(p<0.05)$. The most affected tooth in terms of tooth size reduction was the maxillary lateral incisor and the least affected tooth was the mandibular first molar.

\section{Conclusion:}

Patients with hypodontia have smaller tooth dimensions than control. Tooth size appears to be affected by the degree of hypodontia, with severe hypodontia having a greater effect on tooth size reduction. The findings of this study may contribute to understanding the aetiology of hypodontia and aid the multidisciplinary management of this complex condition.

Keywords: Congenitally, Dimension, Hypodontia, Missing, Size, Tooth.

\section{INTRODUCTION}

Hypodontia is defined as the congenital absence of one or more of the primary or permanent teeth. It is one of the most common dental anomalies [1 - 6] with an overall prevalence of 6.4\% [7]. Different classifications for hypodontia have been reported by various authors according to their severity [8 - 20]. But the most common one includes: mild with 1 to 2 teeth congenitally missing, moderate with 3 to 5 teeth congenitally missing and severe with 6 teeth or more congenitally missing [17, 21]. The latter type is sometimes called oligodontia [5, 7, 22]. Generally, hypodontia occurs more often in females than in males $[8,16,18,23]$. The exact aetiology of hypodontia is not yet well known, but both genetic and environmental factors have been shown to play significant roles [24 - 41].

\footnotetext{
* Address correspondence to this author at the College of Dentistry, King Faisal University, P. O. Box 400, Al Ahsa 31982 , Kingdom of Saudi Arabia; Tel: +966 135898493; Fax: +966 135815271; Emails: kakalef@gmail.com, kkhalaf@kfu.edu.sa
} 
Hypodontia can occur as an isolated dental anomaly or as part of a syndrome. It has been reported that non-syndromic hypodontia occurs in association with other dental anomalies such as delayed eruption of the remaining permanent teeth, reduction in crown and root tooth dimensions, retained primary teeth, ectopic permanent maxillary canines, transposition and rotation of teeth, taurodontism and peg-shaped maxillary lateral incisors and reduced alveolar bone [1, 5, 13 - 15, 37, 38, 42 - 48]. The association between hypodontia and a reduction in tooth size of the remaining dentition (microdontia) has been reported by some studies [15, 17, 25, 37, 38, 43, 46, 49], but others were unable to find such an association [50 - 52]. Furthermore, none of the previous studies have investigated the impact of the severity of hypodontia on tooth size changes of the remaining teeth using the most common classification method of hypodontia and the most common tooth size dimensions namely mesiodistal (MD) and buccolingual (BL) measurements. Therefore, it was important to carry out the present study due to the importance of gaining a detailed knowledge about tooth size of the remaining dentition of patients with hypodontia to aid the diagnosis and treatment planning of this complex dental anomaly which often requires a multidisciplinary approach. Moreover, this knowledge will help to better understand the aetiology of hypodontia.

\section{MATERIAL AND METHODS}

A sample size calculation was carried out to determine the number of subjects required in each comparison group of interest. It was found that 20 subjects will be required in each subgroup to detect a clinically significant difference of $0.9 \mathrm{~mm}$ with 0.05 alpha and 0.2 beta. The study sample consisted of 120 patients with hypodontia divided into three groups of 40 mild ( $\leq 2$ teeth congenitally missing excluding third molars), 40 moderate (3-5 teeth congenitally missing excluding third molars) and 40 severe ( $\geq 6$ teeth congenitally missing excluding third molars) hypodontia; and 40 age and sex matched controls, but with a full complement of the permanent dentition. Each subgroup contained 20 males and 20 females. All hypodontia patients were selected from the Joint Hypodontia Clinic at Aberdeen Dental Hospital, Aberdeen, UK and the control group was selected retrospectively and consecutively from the staff Orthodontic Treatment Waiting List. All subjects were Caucasians, without general medical conditions or syndromes, had no supernumerary teeth and no previous orthodontic treatment. The patient's notes and OPT radiographs were examined to ensure that all patient's details were correct and all the inclusion criteria were met with accuracy including, the congenital absence of teeth for the hypodontia individuals. The age range for the whole sample was 12-18 years and the mean age of the hypodontia group was 13.94 years (standard deviation (SD) 1.8 years) compared with a mean of 14.20 years (SD 2.1 years) for the controls. Study models were constructed for all 160 subjects. The mesiodistal (MD) and buccolingual (BL) measurements were taken from the dental casts of all permanent teeth, excluding the third molars, that were fully erupted, without carious cavities, restorations, excessive tooth wear or severe crowding. The mesiodistal diameter of each tooth was measured with the aid of a digital calliper (Digital Calliper, 0-150 mm, Linear Tools 2001) up to the 2nd decimal digit and as described by Moorrees and Reed [53]. The buccolingual diameter was defined as the maximum length between the buccal and lingual surfaces of the clinical crown of each tooth and perpendicular to the mesiodistal diameter. All measurements were carried out by one trained operator (KK) twice and the mean value of the two measurements was used. Measurement repeatability was assessed using limits of agreement. The mean and standard deviation of the differences were used to construct a range of agreement within which $95 \%$ of the differences in measurements would lie. The method error was carried out on six tooth types from both jaws. The teeth were obtained from 20 randomly selected study models of which 10 were hypodontia patients and 10 control subjects. The teeth were measured twice 4 weeks apart for intra-operator repeatability. There was no systematic bias as the paired sample $t$-test of the differences between the double recordings showed none of the differences were statistically significant $(p>0.05)$. With regard to the random error the method showed a high level of repeatability with a maximum value of the repeatability coefficient of $0.39 \mathrm{~mm}$.

\section{Statistical Analysis}

Statistical analyses were carried out using the Statistical Package for Social Sciences (SPSS Inc., Chicago, Illinois, USA) version 17.0. Distribution of the data was tested using Kolmogorov-Smirnov test which showed a normal distribution $(p>0.05)$ and therefore, parametric tests were used. Comparison between the study and control groups was performed using two-way ANOVA. As the study involved multiple comparisons the subsequent $p$ values were corrected by multiplying the $p$ values by the number of tests.

\section{RESULTS}

Two-way ANOVA revealed no significant interaction between Group and Gender as factor variables and therefore 
groups were compared regardless of genders. Gender differences (within groups) indicated that the males showed larger measurements than females although few findings reached statistical significance.

Table 1 shows comparison of the mesiodistal and buccolingual measurements of the maxillary and mandibular teeth of the mild, moderate and severe hypodontia groups with controls and Table 2 shows Post Hoc Tests of the subgroup comparisons of the mesiodistal and buccolingual measurements of the maxillary and mandibular teeth. Table $\mathbf{3}$ shows percentage reduction in the mesiodistal and buccolingual tooth dimensions of hypodontia patients compared with controls.

Table 1. Comparison of mesiodistal and buccolingual measurements of the maxillary and mandibular teeth according to severity of hypodontia.

\begin{tabular}{|c|c|c|c|c|c|c|c|c|c|c|}
\hline \multirow[t]{2}{*}{ Tooth } & \multirow[t]{2}{*}{ Measurement } & \multicolumn{2}{|l|}{ Group I } & \multicolumn{2}{|c|}{ Group II } & \multicolumn{2}{|c|}{ Group III } & \multicolumn{2}{|c|}{ Group IV } & \multirow[t]{2}{*}{ P-value } \\
\hline & & Mean \pm SD & $\mathbf{N}$ & Mean \pm SD & $\mathbf{N}$ & Mean \pm SD & $\mathbf{N}$ & Mean \pm SD & $\mathbf{N}$ & \\
\hline \multirow[t]{2}{*}{ U1 } & MD & $7.89 \pm 0.53$ & 40 & $7.20 \pm 0.80$ & 39 & $6.71 \pm 0.79$ & 40 & $8.14 \pm 0.67$ & 40 & $<0.001$ \\
\hline & BL & $6.51 \pm 0.70$ & 40 & $6.20 \pm 0.64$ & 39 & $5.59 \pm 0.86$ & 40 & $7.05 \pm 0.37$ & 40 & $<0.001$ \\
\hline \multirow[t]{2}{*}{ U2 } & MD & $5.32 \pm 1.01$ & 25 & $4.87 \pm 0.80$ & 24 & $4.25 \pm 1.14$ & 22 & $6.28 \pm 0.55$ & 40 & $<0.001$ \\
\hline & BL & $5.46 \pm 0.63$ & 25 & $5.40 \pm 0.96$ & 24 & $4.31 \pm 0.78$ & 21 & $6.12 \pm 0.47$ & 40 & $<0.001$ \\
\hline \multirow[t]{2}{*}{$\mathbf{U 3}$} & MD & $6.99 \pm 0.52$ & 40 & $6.65 \pm 0.66$ & 36 & $6.25 \pm 0.64$ & 34 & $7.07 \pm 0.59$ & 40 & 0.334 \\
\hline & BL & $7.23 \pm 0.84$ & 40 & $6.94 \pm 0.87$ & 36 & $6.31 \pm 0.66$ & 34 & $7.90 \pm 0.58$ & 40 & $<0.001$ \\
\hline \multirow[t]{2}{*}{$\mathbf{U 4}$} & MD & $5.76 \pm 0.50$ & 40 & $5.29 \pm 0.73$ & 38 & $4.96 \pm 0.50$ & 19 & $6.01 \pm 0.41$ & 40 & $<0.001$ \\
\hline & BL & $8.57 \pm 0.66$ & 40 & $8.19 \pm 0.73$ & 38 & $7.32 \pm 0.52$ & 21 & $9.31 \pm 0.48$ & 40 & $<0.001$ \\
\hline \multirow[t]{2}{*}{ U5 } & MD & $5.74 \pm 0.54$ & 39 & $5.39 \pm 0.65$ & 34 & $5.02 \pm 0.48$ & 22 & $5.94 \pm 0.60$ & 40 & $<0.001$ \\
\hline & BL & $8.73 \pm 0.64$ & 39 & $8.39 \pm 0.71$ & 35 & $8.08 \pm 0.60$ & 22 & $9.45 \pm 0.37$ & 40 & $<0.001$ \\
\hline \multirow[t]{2}{*}{ U6 } & MD & $9.64 \pm 0.68$ & 40 & $9.00 \pm 0.79$ & 39 & $8.57 \pm 0.89$ & 36 & $9.78 \pm 0.48$ & 40 & $<0.001$ \\
\hline & BL & $10.90 \pm 0.59$ & 40 & $10.53 \pm 0.72$ & 39 & $9.89 \pm 0.49$ & 35 & $11.02 \pm 0.39$ & 40 & $<0.001$ \\
\hline \multirow[t]{2}{*}{ L1 } & MD & $5.11 \pm 0.53$ & 39 & $4.56 \pm 0.76$ & 35 & $4.25 \pm 0.69$ & 29 & $5.18 \pm 0.50$ & 40 & $<0.001$ \\
\hline & BL & $5.42 \pm 0.79$ & 39 & $5.26 \pm 0.60$ & 35 & $4.64 \pm 0.48$ & 29 & $6.01 \pm 0.36$ & 40 & $<0.001$ \\
\hline \multirow[t]{2}{*}{ L2 } & MD & $5.49 \pm 0.56$ & 40 & $4.83 \pm 0.57$ & 39 & $4.60 \pm 0.67$ & 33 & $5.50 \pm 0.39$ & 40 & $<0.001$ \\
\hline & BL & $5.86 \pm 0.74$ & 40 & $5.57 \pm 0.54$ & 39 & $5.00 \pm 0.69$ & 34 & $6.21 \pm 0.34$ & 40 & $<0.001$ \\
\hline \multirow[t]{2}{*}{$\mathbf{L 3}$} & MD & $6.16 \pm 0.60$ & 40 & $5.59 \pm 0.56$ & 40 & $5.35 \pm 0.47$ & 38 & $6.45 \pm 0.40$ & 40 & $<0.001$ \\
\hline & BL & $6.73 \pm 0.83$ & 40 & $6.56 \pm 0.63$ & 40 & $5.83 \pm 0.68$ & 38 & $7.38 \pm 0.43$ & 40 & $<0.001$ \\
\hline \multirow[t]{2}{*}{ L4 } & MD & $6.14 \pm 0.65$ & 40 & $5.57 \pm 0.80$ & 39 & $5.40 \pm 0.55$ & 28 & $6.55 \pm 0.50$ & 40 & $<0.001$ \\
\hline & BL & $7.51 \pm 0.59$ & 40 & $7.51 \pm 0.61$ & 39 & $7.03 \pm 0.38$ & 28 & $8.03 \pm 0.42$ & 40 & $<0.001$ \\
\hline \multirow[t]{2}{*}{ L5 } & MD & $6.43 \pm 0.61$ & 36 & $5.80 \pm 0.98$ & 25 & $5.46 \pm 0.76$ & 9 & $6.53 \pm 0.57$ & 40 & $<0.001$ \\
\hline & BL & $8.09 \pm 0.58$ & 36 & $7.77 \pm 0.90$ & 24 & $7.18 \pm 0.70$ & 9 & $8.56 \pm 0.33$ & 40 & $<0.001$ \\
\hline \multirow[t]{2}{*}{ L6 } & MD & $9.87 \pm 0.85$ & 40 & $9.44 \pm 0.76$ & 39 & $8.88 \pm 0.74$ & 37 & $9.94 \pm 0.52$ & 40 & $<0.001$ \\
\hline & BL & $10.26 \pm 0.60$ & 40 & $10.05 \pm 0.62$ & 40 & $9.40 \pm 0.58$ & 37 & $10.30 \pm 0.42$ & 40 & $<0.001$ \\
\hline
\end{tabular}

U: upper; L: lower; SD: standard deviation; group I: mild hypodontia; group II: moderate hypodontia; group III: severe hypodontia; and group IV: normal controls; MD: mesiodistal; BL: buccolingual.

Table 2. Post Hoc Tests of subgroup comparison of mesiodistal and buccolingual measurements of the maxillary and mandibular teeth.

\begin{tabular}{|c|c|c|c|c|c|c|c|}
\hline \multirow[t]{2}{*}{ Tooth } & \multirow[t]{2}{*}{ Measurement } & \multicolumn{6}{|c|}{ Subgroup comparisons } \\
\hline & & I-II & I-III & I-IV & II-III & II-IV & III-IV \\
\hline \multirow[t]{2}{*}{ U1 } & MD & $<0.001$ & $<0.001$ & $<0.001$ & $<0.001$ & $<0.001$ & $<0.001$ \\
\hline & BL & .024 & $<0.001$ & $<0.001$ & $<0.001$ & $<0.001$ & $<0.001$ \\
\hline \multirow[t]{2}{*}{ U2 } & MD & .058 & $<0.001$ & $<0.001$ & .012 & $<0.001$ & $<0.001$ \\
\hline & BL & .747 & $<0.001$ & $<0.001$ & $<0.001$ & $<0.001$ & $<0.001$ \\
\hline \multirow[t]{2}{*}{ U3 } & MD & .161 & .905 & .991 & .144 & .158 & .914 \\
\hline & BL & .073 & $<0.001$ & $<0.001$ & $<0.001$ & $<0.001$ & $<0.001$ \\
\hline \multirow[t]{2}{*}{ U4 } & MD & $<0.001$ & $<0.001$ & .012 & .010 & $<0.001$ & $<0.001$ \\
\hline & BL & .006 & $<0.001$ & $<0.001$ & $<0.001$ & $<0.001$ & $<0.001$ \\
\hline \multirow[t]{2}{*}{ U5 } & MD & .001 & $<0.001$ & .040 & .002 & $<0.001$ & $<0.001$ \\
\hline & BL & .016 & $<0.001$ & $<0.001$ & .049 & $<0.001$ & $<0.001$ \\
\hline
\end{tabular}


(Table 2) contd.....

\begin{tabular}{|c|c|c|c|c|c|c|c|}
\hline \multirow[t]{2}{*}{ Tooth } & \multirow[t]{2}{*}{ Measurement } & \multicolumn{6}{|c|}{ Subgroup comparisons } \\
\hline & & I-II & I-III & I-IV & II-III & II-IV & III-IV \\
\hline \multirow[t]{2}{*}{ U6 } & MD & $<0.001$ & $<0.001$ & .380 & .007 & $<0.001$ & $<0.001$ \\
\hline & BL & .002 & $<0.001$ & .276 & $<0.001$ & $<0.001$ & $<0.001$ \\
\hline \multirow[t]{2}{*}{ L1 } & MD & $<0.001$ & $<0.001$ & .541 & .020 & $<0.001$ & $<0.001$ \\
\hline & BL & .185 & $<0.001$ & $<0.001$ & $<0.001$ & $<0.001$ & $<0.001$ \\
\hline \multirow[t]{2}{*}{$\mathbf{L 2}$} & MD & $<0.001$ & $<0.001$ & .938 & .055 & $<0.001$ & $<0.001$ \\
\hline & BL & .016 & $<0.001$ & .003 & $<0.001$ & $<0.001$ & $<0.001$ \\
\hline \multirow[t]{2}{*}{$\mathbf{L 3}$} & MD & $<0.001$ & $<0.001$ & .007 & .026 & $<0.001$ & $<0.001$ \\
\hline & BL & .249 & $<0.001$ & $<0.001$ & $<0.001$ & $<0.001$ & $<0.001$ \\
\hline \multirow[t]{2}{*}{$\mathbf{L 4}$} & MD & $<0.001$ & $<0.001$ & .002 & .220 & $<0.001$ & $<0.001$ \\
\hline & BL & .975 & $<0.001$ & $<0.001$ & $<0.001$ & $<0.001$ & $<0.001$ \\
\hline \multirow[t]{2}{*}{ L5 } & MD & $<0.001$ & $<0.001$ & .423 & .106 & $<0.001$ & $<0.001$ \\
\hline & BL & .042 & $<0.001$ & .001 & .013 & $<0.001$ & $<0.001$ \\
\hline \multirow[t]{2}{*}{ L6 } & MD & .004 & $<0.001$ & .624 & $<0.001$ & .001 & $<0.001$ \\
\hline & BL & .087 & $<0.001$ & .700 & $<0.001$ & .037 & $<0.001$ \\
\hline
\end{tabular}

U: upper; L: lower; group I: mild hypodontia; group II: moderate hypodontia; group III: severe hypodontia; and group IV: normal controls; MD: mesiodistal; BL: buccolingual.

As it can be seen from Tables 1-3 all hypodontia patients had statistically significantly smaller MD and BL tooth dimensions than those in the control except MD of the maxillary canine in all hypodontia groups and the following measurements in the mild hypodontia group: MD and BL of the first molars and MD of the mandibular incisors and mandibular second premolar. In addition, severe hypodontia group had greater reduction in the MD and BL measurements than moderate hypodontia group and this in turn had a greater reduction in the aforementioned measurements than mild hypodontia group when compared with controls. The ranges for percentage reduction in the mesiodistal tooth dimension of the mild, moderate and severe hypodontia groups were $0.72-15.32 \%, 4.91-22.47 \%$ and $10.65-32.35 \%$ respectively; and the ranges for percentage reduction in the buccolingual tooth dimension of the mild, moderate and severe hypodontia groups were $0.45-11.85 \%, 2.48-12.51 \%$ and $8.79-29.53 \%$ respectively. The most affected tooth in terms of tooth size reduction was found to be the maxillary lateral incisor and the least affected tooth was the mandibular first molar.

Table 3. Percentage reduction in the mesiodistal and buccolingual tooth dimensions of hypodontia patients compared with controls.

\begin{tabular}{|l|c|c|c|c|c|c|}
\hline Tooth & \multicolumn{2}{|c|}{ Mild hypodontia } & \multicolumn{2}{c|}{ Moderate hypodontia } & \multicolumn{2}{c|}{ Severe hypodontia } \\
\hline & MD & BL & MD & BL & MD & BL \\
\hline U1 & 3.16 & 7.62 & 8.74 & 12.03 & 14.89 & 20.72 \\
\hline U2 & 15.32 & 11.85 & 22.47 & 10.80 & 32.35 & 29.53 \\
\hline U3 & 1.10 & 8.44 & 4.91 & 12.15 & 10.65 & 20.04 \\
\hline U4 & 4.14 & 7.98 & 12.02 & 12.07 & 17.40 & 21.42 \\
\hline U5 & 3.42 & 7.65 & 9.19 & 11.18 & 15.49 & 14.52 \\
\hline U6 & 1.35 & 1.13 & 7.95 & 4.47 & 12.32 & 10.29 \\
\hline L1 & 1.40 & 9.77 & 11.87 & 12.51 & 17.86 & 22.71 \\
\hline L2 & 0.16 & 5.70 & 12.25 & 10.33 & 16.36 & 19.45 \\
\hline L3 & 4.58 & 8.85 & 13.33 & 11.08 & 17.11 & 20.95 \\
\hline L4 & 6.21 & 6.48 & 14.96 & 6.52 & 17.60 & 12.43 \\
\hline L5 & 1.53 & 5.57 & 11.21 & 9.33 & 16.46 & 16.13 \\
\hline L6 & 0.72 & 0.45 & 5.10 & 2.48 & 10.66 & 8.79 \\
\hline
\end{tabular}

U: upper; L: lower; MD: mesiodistal; BL: buccolingual.

\section{DISCUSSION}

The current study has shown, generally, there were no statistically significant differences in the MD and BL tooth size dimensions between males and females. Similar findings were also reported by many other previous investigations [13, 15, 46, 49, 54] but, Brook et al. [38], have shown sexual dimorphism for the canine teeth of the hypodontia groups in comparison with controls with males having a greater tooth size difference. They attributed this difference due to the fact that tooth size of the canine teeth in normal males are greater than that in normal females. 
In the current study the congenital absence of teeth was found to be associated with reduction in the MD and BL dimensions of the remaining dentition when patients with hypodontia were compared with controls. This finding agrees with previous studies $[13,15,25,38,46,49,54]$ which have shown an association between hypodontia and microdontia of the remaining dentition. Furthermore, McKeown and her co-workers [46] found the unaffected relatives of hypodontia patients were also affected by microdontia, indicating that hypodontia and microdontia may form parts of a genetically determined condition. But, Wisth et al. [50], were unable to find statistically significant differences in the mesiodistal dimension between a hypodontia and a control group. Careful inspection of our findings does show that our findings corresponds fairly well with Wisth's et al., study as the latter authors investigated only the MD dimension of the first molars and central incisors and their study group was predominantly of mild hypodontia with one or two teeth congenitally missing. Küchler et al. [51], in their study of clinical records and orthopantamograms from 1198 patients treated at the Federal University of Rio de Janeiro's Continuing Education Clinical Program in Pediatric Dentistry were unable to find a statistically significant difference in tooth size between 56 hypodontia patients and 111 control subjects. The difference between the findings of our study and those of the latter one was due to the fact that the latter study did investigate tooth size of only the maxillary lateral incisors using a clinical observation, rather than odontometric measurements, which is subjective in nature and thus prone to great inaccuracy. Chung et al. [52], reported that hypodontia was not associated with changes in tooth size. The difference between this study's finding and the findings in our study may be attributed to the differences between the two studies in term of sampling whereby Chung's et al., sample was a referred orthodontic population, racial differences where Chung's et al., sample was a Korean population and the control used in Chung's et al., study was a historical control obtained from 94 Korean adults with a Class I normal occlusion [55]. Moreover, Chung's et al., investigated only the MD dimension of the remaining dentition in a predominantly mild hypodontia group.

Another finding in the current study was that, as the severity of hypodontia has increased the impact on tooth size reduction of the remaining dentition has also increased. This finding was in accordance with previous investigations $[49,56]$. In contrast to these findings Brook et al. [38], did find a correlation between the extent of tooth size reduction and the number of congenitally missing teeth in hypodontia patients, but this was not statistically significant when males and females were treated separately. This was most probably due to the smaller sample size when the sexes were considered independently. The moderate hypodontia group in the current study has shown less statistically significant differences of tooth size reduction than that in Gungor and Turkkahraman's study [49] and the opposite holds true for the severe hypodontia group. This may be explained by the different criteria used to classify the mild hypodontia group in the two studies whereby Gungor and Turkkahraman classified the mild hypodontia subjects as those who had 2-5 congenitally missing teeth and thus patients with one congenitally missing tooth were not considered in their mild hypodontia group which may have enhanced the strength of the relationship between tooth size reduction and the number of congenitally missing teeth. With regards to the greater number of statistically significant differences of tooth size reduction in the current study than in Gungor and Turkkahraman's study, this may be attributed to the smaller sample size of the severe hypodontia male subgroup in the latter study which did not allow for some of the differences to reach the statistical significance levels.

One interesting finding in the current study was that more buccolingual dimensions were found to be reduced in the mild hypodontia group than in moderate and severe hypodontia groups when compared with controls. This may suggest a different aetiology for the mild hypodontia group to that for moderate and severe hypodontia groups. Considering that in developing teeth, the mesiodistal dimension is determined before the labiolingual one [17] and that both genetic and environmental factors have been shown to play significant roles in the aetiology of hypodontia [24 - 41] it may be that the environmental factors play a more significant role in the aetiology of mild hypodontia in comparison with moderate and severe hypodontia.

In this study, the greatest tooth size reduction for both MD and BL dimensions was found for the maxillary lateral incisors. Similar finding was reported by previous studies, but for only the MD dimension [38, 49]. The differences between studies for the impact of congenitally missing teeth on reduction of the BL dimension may be attributed to its later completion of development compared with the MD dimension [57] which makes it more prone to the environmental insults and thus a greater variability.

The results of this study will help the multidisciplinary team to manage patients with hypodontia during all stages including the diagnosis, treatment planning and carrying out the treatment. Space analysis as well as Kestling set-ups should carefully be carried out in hypodontia patients to arrive at an optimal treatment plan and decide whether to open, close or redistribute spaces. Intra-arch spaces in hypodontia patients are often greater than the number of congenitally 
missing teeth and especially so as the severity of the condition increases due to the extra spaces available from the reduced MD dimensions of the remaining teeth. Moreover, reduction of tooth size in hypodontia patients will make tooth movements more anchorage demanding and accurate placement of the brackets more challenging to the orthodontist. Furthermore, Composite build-ups in hypodontia patients are often required by the restorative dentist to close the excessive spaces, improve tooth form and allow for a good inter-arch relationship.

\section{CONCLUSION}

1. Patients with hypodontia had smaller mesiodistal and buccolingual tooth dimensions than control.

2. The more severe the hypodontia the greater reduction in tooth size of the remaining dentition.

3. The most affected tooth in terms of tooth size reduction was the maxillary lateral incisor and the least affected tooth was the mandibular first molar.

\section{CONFLICT OF INTEREST}

The author confirms that this article content has no conflict of interest.

\section{ACKNOWLEDGEMENTS}

Declared none.

\section{REFERENCES}

[1] Bäckman B, Wahlin YB. Variations in number and morphology of permanent teeth in 7-year-old Swedish children. Int J Paediatr Dent 2001; 11(1): 11-7. [http://dx.doi.org/10.1046/j.1365-263x.2001.00205.x] [PMID: 11309867]

[2] Endo T, Ozoe R, Kubota M, Akiyama M, Shimooka S. A survey of hypodontia in Japanese orthodontic patients. Am J Orthod Dentofacial Orthop 2006; 129(1): 29-35.

[http://dx.doi.org/10.1016/j.ajodo.2004.09.024] [PMID: 16443475]

[3] Altug-Atac AT, Erdem D. Prevalence and distribution of dental anomalies in orthodontic patients. Am J Orthod Dentofacial Orthop 2007; 131(4): 510-4.

[http://dx.doi.org/10.1016/j.ajodo.2005.06.027] [PMID: 17418718]

[4] Goya HA, Tanaka S, Maeda T, Akimoto Y. An orthopantomographic study of hypodontia in permanent teeth of Japanese pediatric patients. J Oral Sci 2008; 50(2): 143-50. [http://dx.doi.org/10.2334/josnusd.50.143] [PMID: 18587203]

[5] De Coster PJ, Marks LA, Martens LC, Huysseune A. Dental agenesis: genetic and clinical perspectives. J Oral Pathol Med 2009 ; $38(1)$ : 1-17. [http://dx.doi.org/10.1111/j.1600-0714.2008.00699.x] [PMID: 18771513]

[6] AlShahrani I, Togoo RA, AlQarni MA. A review of hypodontia: classification, prevalence, etiology, associated anomalies, clinical implications and treatment options. World J Dent 2013; 4(2): 117-25. [http://dx.doi.org/10.5005/jp-journals-10015-1216]

[7] Khalaf K, Miskelly J, Voge E, Macfarlane TV. Prevalence of hypodontia and associated factors: a systematic review and meta-analysis. J Orthod 2014; 41(4): 299-316.

[http://dx.doi.org/10.1179/1465313314Y.0000000116] [PMID: 25404667]

[8] Brook AH. Dental anomalies of number, form and size: their prevalence in British schoolchildren. J Int Assoc Dent Child 1974; 5(2): $37-53$. [PMID: 4535299]

[9] Dhanrajani PJ. Hypodontia: etiology, clinical features, and management. Quintessence Int 2002; 33(4): 294-302. [PMID: 11989379]

[10] Kirzioğlu Z, Köseler Sentut T, Ozay Ertürk MS, Karayilmaz H. Clinical features of hypodontia and associated dental anomalies: a retrospective study. Oral Dis 2005; 11(6): 399-404. [http://dx.doi.org/10.1111/j.1601-0825.2005.01138.x] [PMID: 16269033]

[11] Wu CC, Wong RW, Hagg U. A review of hypodontia: The possible etiologies and orthodontic, surgical and restorative treatment options conventional and futuristic. Hong Kong Dent J 2007; 4: 113-21.

[12] Pemberton TJ, Das P, Patel PI. Hypodontia: Genetics and future perspectives. Braz J Oral Sci 2005; 4: 695-706.

[13] Schalk-van der Weide Y, Steen WH, Bosman F. Distribution of missing teeth and tooth morphology in patients with oligodontia. ASDC J Dent Child 1992; 59(2): 133-40. [PMID: 1583198]

[14] Goodman JR, Jones SP, Hobkirk JA, King PA. Hypodontia: 1. Clinical features and the management of mild to moderate hypodontia. Dent Update 1994; $21: 381-4$. 
[15] Schalk-van der Weide Y, Bosman F. Tooth size in relatives of individuals with oligodontia. Arch Oral Biol 1996; 41(5): 469-72. [http://dx.doi.org/10.1016/0003-9969(95)00143-3] [PMID: 8809310]

[16] Vastardis H. The genetics of human tooth agenesis: new discoveries for understanding dental anomalies. Am J Orthod Dentofacial Orthop 2000; 117(6): 650-6.

[http://dx.doi.org/10.1016/S0889-5406(00)70173-9] [PMID: 10842107]

[17] Brook AH, Elcock C, al-Sharood MH, McKeown HF, Khalaf K, Smith RN. Further studies of a model for the etiology of anomalies of tooth number and size in humans. Connect Tissue Res 2002; 43(2-3): 289-95. [http://dx.doi.org/10.1080/03008200290000718] [PMID: 12489172]

[18] Polder BJ, Van't Hof MA, Van der Linden FP, Kuijpers-Jagtman AM. A meta-analysis of the prevalence of dental agenesis of permanent teeth. Community Dent Oral Epidemiol 2004; 32(3): 217-26. [http://dx.doi.org/10.1111/j.1600-0528.2004.00158.x] [PMID: 15151692]

[19] Fekonja A. Hypodontia in orthodontically treated children. Eur J Orthod 2005; 27(5): 457-60. [http://dx.doi.org/10.1093/ejo/cji027] [PMID: 16043466]

[20] Rakhshan V. Meta-analysis and systematic review of factors biasing the observed prevalence of congenitally missing teeth in permanent dentition excluding third molars. Prog Orthod 2013; 14: 33. [http://dx.doi.org/10.1186/2196-1042-14-33] [PMID: 24325806]

[21] Hobkirk JA, Gill DS, Jones SP, Hemmings KW, et al. Hypodontia: A team approach to management. $1^{\text {st }}$ ed. Chichester: Wiley-Blackwell 2011.

[22] Hosur MB, Puranik RS, Vanaki SS. Oligodontia: A case report and review of literature. World J Dent 2011; 2(3): 259-62. [http://dx.doi.org/10.5005/jp-journals-10015-1093]

[23] Mattheeuws N, Dermaut L, Martens G. Has hypodontia increased in Caucasians during the 20 $0^{\text {th }}$ century? A meta-analysis. Eur J Orthod 2004; 26(1): 99-103. [http://dx.doi.org/10.1093/ejo/26.1.99] [PMID: 14994889]

[24] Boruchov MJ, Green LJ. Hypodontia in human twins and families. Am J Orthod 1971; 60(2): 165-74. [http://dx.doi.org/10.1016/0002-9416(71)90032-7] [PMID: 5283998]

[25] Brook AH. A unifying aetiological explanation for anomalies of human tooth number and size. Arch Oral Biol 1984; 29(5): 373-8. [http://dx.doi.org/10.1016/0003-9969(84)90163-8] [PMID: 6611147]

[26] Vastardis H, Karimbux N, Guthua SW, Seidman JG, Seidman CE. A human MSX1 homeodomain missense mutation causes selective tooth agenesis. Nat Genet 1996; 13(4): 417-21. [http://dx.doi.org/10.1038/ng0896-417] [PMID: 8696335]

[27] Ahmad W, Brancolini V, ul Faiyaz MF, et al. A locus for autosomal recessive hypodontia with associated dental anomalies maps to chromosome 16q12.1. Am J Hum Genet 1998; 62(4): 987-91. [http://dx.doi.org/10.1086/301799] [PMID: 9529357]

[28] Goldenberg M, Das P, Messersmith M, Stockton DW, Patel PI, D’Souza RN. Clinical, radiographic, and genetic evaluation of a novel form of autosomal-dominant oligodontia. J Dent Res 2000; 79(7): 1469-75. [http://dx.doi.org/10.1177/00220345000790070701] [PMID: 11005730]

[29] Arte S, Nieminen P, Apajalahti S, Haavikko K, Thesleff I, Pirinen S. Characteristics of incisor-premolar hypodontia in families. J Dent Res 2001; 80(5): 1445-50. [http://dx.doi.org/10.1177/00220345010800051201] [PMID: 11437217]

[30] Pirinen S, Kentala A, Nieminen P, Varilo T, Thesleff I, Arte S. Recessively inherited lower incisor hypodontia. J Med Genet 2001; 38(8): 551-6. [http://dx.doi.org/10.1136/jmg.38.8.551] [PMID: 11494968]

[31] Alaluusua S, Calderara P, Gerthoux PM, et al. Developmental dental aberrations after the dioxin accident in Seveso. Environ Health Perspect 2004; 112(13): 1313-8.

[http://dx.doi.org/10.1289/ehp.6920] [PMID: 15345345]

[32] Marec-Berard P, Azzi D, Chaux-Bodard AG, Lagrange H, Gourmet R, Bergeron C. Long-term effects of chemotherapy on dental status in children treated for nephroblastoma. Pediatr Hematol Oncol 2005; 22(7): 581-8. [http://dx.doi.org/10.1080/08880010500198848] [PMID: 16166051]

[33] Thesleff I. The genetic basis of tooth development and dental defects. Am J Med Genet A 2006; 140(23): $2530-5$. [http://dx.doi.org/10.1002/ajmg.a.31360] [PMID: 16838332]

[34] Cobourne MT. Familial human hypodontia-is it all in the genes? Br Dent J 2007; 203(4): 203-8. [http://dx.doi.org/10.1038/bdj.2007.732] [PMID: 17721480]

[35] Keller JM, Huet-Hudson YM, Leamy LJ. Qualitative effects of dioxin on molars vary among inbred mouse strains. Arch Oral Biol 2007; 52(5): 450-4. [http://dx.doi.org/10.1016/j.archoralbio.2006.10.017] [PMID: 17141729]

[36] Yamaguchi T, Tomoyasu Y, Nakadate T, Oguchi K, Maki K. Allergy as a possible predisposing factor for hypodontia. Eur J Orthod 2008; 
30(6): $641-4$

[http://dx.doi.org/10.1093/ejo/cjn043] [PMID: 18687988]

[37] Brook AH, Elcock C, Aggarwal M, et al. Tooth dimensions in hypodontia with a known PAX9 mutation. Arch Oral Biol 2009; 54(Suppl. 1): S57-62. a [http://dx.doi.org/10.1016/j.archoralbio.2008.05.017] [PMID: 18653171]

[38] Brook AH, Griffin RC, Smith RN, et al. Tooth size patterns in patients with hypodontia and supernumerary teeth. Arch Oral Biol 2009; 54(Suppl. 1): S63-70. b

[http://dx.doi.org/10.1016/j.archoralbio.2008.05.016] [PMID: 18675390]

[39] Parkin N, Elcock C, Smith RN, Griffin RC, Brook AH. The aetiology of hypodontia: the prevalence, severity and location of hypodontia within families. Arch Oral Biol 2009; 54(Suppl. 1): S52-6. [http://dx.doi.org/10.1016/j.archoralbio.2008.11.002] [PMID: 19100963]

[40] Nieminen P. Genetic basis of tooth agenesis. J Exp Zoolog B Mol Dev Evol 2009; 312B(4): 320-42. [http://dx.doi.org/10.1002/jez.b.21277] [PMID: 19219933]

[41] Pedersen LB, Clausen N, Schrøder H, Schmidt M, Poulsen S. Microdontia and hypodontia of premolars and permanent molars in childhood cancer survivors after chemotherapy. Int J Paediatr Dent 2012; 22(4): 239-43. [http://dx.doi.org/10.1111/j.1365-263X.2011.01199.x] [PMID: 22092748]

[42] Graber LW. Congenital absence of teeth: a review with emphasis on inheritance patterns. J Am Dent Assoc 1978; 96(2): 266-75. [http://dx.doi.org/10.14219/jada.archive.1978.0054] [PMID: 342579]

[43] Lai PY, Seow WK. A controlled study of the association of various dental anomalies with hypodontia of permanent teeth. Pediatr Dent 1989; 11(4): 291-6. [PMID: 2639323]

[44] Peck S, Peck L, Kataja M. Site-specificity of tooth agenesis in subjects with maxillary canine malpositions. Angle Orthod 1996; 66(6): 473-6. [PMID: 8974184]

[45] Baccetti T. Tooth rotation associated with aplasia of nonadjacent teeth. Angle Orthod 1998; 68(5): 471-4. [PMID: 9770106]

[46] McKeown HF, Robinson DL, Elcock C, al-Sharood M, Brook AH. Tooth dimensions in hypodontia patients, their unaffected relatives and a control group measured by a new image analysis system. Eur J Orthod 2002; 24(2): 131-41. [http://dx.doi.org/10.1093/ejo/24.2.131] [PMID: 12001549]

[47] Peck S, Peck L, Kataja M. Concomitant occurrence of canine malposition and tooth agenesis: evidence of orofacial genetic fields. Am J Orthod Dentofacial Orthop 2002; 122(6): 657-60. [http://dx.doi.org/10.1067/mod.2002.129915] [PMID: 12490878]

[48] Wu CC, Wong RW, Hägg U. A review of hypodontia: The possible etiologies and orthodontic, surgical and restorative treatment optionsconventional and futuristic. Hong Kong Dent J 2007; 4: 113-21.

[49] Gungor AY, Turkkahraman H. Tooth sizes in nonsyndromic hypodontia patients. Angle Orthod 2013; 83(1): 16-21. [http://dx.doi.org/10.2319/011112-23.1] [PMID: 22578281]

[50] Wisth PJ, Thunold K, Böe OE. Frequency of hypodontia in relation to tooth size and dental arch width. Acta Odontol Scand 1974; 32(3): 201-6. [http://dx.doi.org/10.3109/00016357409002548] [PMID: 4155221]

[51] Küchler EC, Risso PA, Costa MdeC, Modesto A, Vieira AR. Studies of dental anomalies in a large group of school children. Arch Oral Biol 2008; 53(10): 941-6. [http://dx.doi.org/10.1016/j.archoralbio.2008.04.003] [PMID: 18490001]

[52] Chung CJ, Han JH, Kim KH. The pattern and prevalence of hypodontia in Koreans. Oral Dis 2008; 14(7): 620-5. [http://dx.doi.org/10.1111/j.1601-0825.2007.01434.x] [PMID: 18248591]

[53] Moorrees CF, Reed RB. Correlations among crown diameters of human teeth. Arch Oral Biol 1964; 9: 685-97. [http://dx.doi.org/10.1016/0003-9969(64)90080-9] [PMID: 14219519]

[54] Woodworth DA, Sinclair PM, Alexander RG. Bilateral congenital absence of maxillary lateral incisors: a craniofacial and dental cast analysis. Am J Orthod 1985; 87(4): 280-93. [http://dx.doi.org/10.1016/0002-9416(85)90003-X] [PMID: 3857005]

[55] Kim DS, Kim YJ, Choi JH, Han JH. A study of Korean Norm about tooth size and ratio in Korean adults with normal occlusion. Korean J Orthod 2001; 31: 505-15.

[56] Schalk-van der Weide Y. Oligodontia, a clinical, radiographic and genetic evaluation. Netherland: University of Utrecht 1992.

[57] Schalk-van der Weide Y, Steen WH, Beemer FA, Bosman F. Reductions in size and left-right asymmetry of teeth in human oligodontia. Arch Oral Biol 1994; 39(11): 935-9.

[http://dx.doi.org/10.1016/0003-9969(94)90076-0] [PMID: 7695506] 